\title{
Return Predictability of Stock Price Index in Tehran Stock Exchange
}

\author{
Mohsen Mehrara \\ Faculty of Economics, University of Tehran, Kargar-e-shomali, Po Box 14166-6445 \\ Tehran, Iran \\ E-mail address: mmehrara@ut.ac.ir
}

\begin{abstract}
The question of whether asset price changes are predictable has long been the subject of many studies. Many studies, using historical returns based on random walk tests, have shown that stock return is not predictable. We study return predictability of the Tehran Exchange Price Index (TEPIX) based on monthly data from 2000 to 2011 . For forecasting the return, we used a recursive estimation method in which the parameter estimates were updated recursively in light of new weekly observations, and also its regressors were changed recursively according to the Schwarz Bayesian Criterion. The results show that the daily stock returns are not predictable using publicly available information.
\end{abstract}

Keywords: Stock Market; Tehran Exchange Price Index; Forecasting

JEL classification: F31; G17

\section{INTRODUCTION}

The question of whether asset price changes are predictable has long been the subject of many studies. There is an old joke among economists, about an economist walking the street with his mate. They saw a $\$ 100$ bill on the ground, and as the mate reaches down to pick it up, the economist says, 'Don't bother, if it was a genuine $\$ 100$ bill, someone would have already picked it up'. This funny example of economic logic conveys the concept of efficient markets hypothesis $(\mathrm{EMH})$. A market is said to be informationally efficient, if prices in the market completely reflect all the available and relevant information. From this perspective, in an efficient market, price changes only because of the arrival of new information. But, because future information cannot be predicted, it is also impossible to forecast future price changes according to the information set available, so it is not possible to make economic profit using the available information (see Malkiel, 1992). The origins of the EMH can be found in the works of Fama and Samuelson and Roberts who had been working independently on the issue in the 1960s. It is generally accepted that there are three forms of efficiency depending on the information set $\Omega_{t}$ :

- Weak form: No investor can earn excess returns using historical prices.

- Semi-strong form: No investor can earn excess returns using historical prices and all publicly available information. 
- Strong form: No investor can earn excess returns using any information, including historical prices, publicly available information, and private or insider information.

This article reports the results related to testing the predictability of monthly return of the Tehran Exchange Price Index (TEPIX) from 2000:1 to 2011:12. It will be shown that the stock returns $\left(\mathrm{r}_{\mathrm{t}} \approx \log \left(\mathrm{p}_{\mathrm{t}}\right)-\log \left(\mathrm{p}_{\mathrm{t}-1}\right)\right)$ are not predictable using publicly available information, so the last two forms of the market efficiency are not rejected.

The remainder of this paper is organized as follows: section 2 describes the methodology which was used for forecasting the returns. Section 3 presents the empirical results. Section 4 concludes.

\section{METHODOLOGY}

\section{1. Proposed method for forecasting}

Many articles estimate their forecasting model on the basis of the entire sample of available observations or on subsamples of the data, while in fact, traders can only have access to historical data, that is, they cannot estimate parameters based on the entire sample. In addition, the articles ignore the problem of "model uncertainty", because they use a particular model for forecasting over time, while as time passes, more new information emerge, and the added information may help the trader to improve the forecasting model, so it is not reasonable to use a particular forecasting model with certainty over time. To deal with these two problems, at each point in time, we use only historical data to choose a model according to a model selection criterion, which in this article the criterion is $\mathrm{R}^{2}$; then one-step-ahead forecasts are computed using the model. This method is done in three step as follows (see Pesaran andTimmermann, 1995, 2000; Amemiya, 1980; Bossaerts and Hillion, 1999):

1) In the first step, the forecasting model is determined: first, there is no additional regressor in the model, then the regressor that maximizes $\mathrm{R}^{2}$ is added; then the regressor that leads to the largest increase in $\mathrm{R}^{2}$ is inserted into the model; next each of the two regressors is compared individually with all the variables that are outside the model, and it is checked whether it is possible to increase $\mathrm{R}^{2}$ by swapping each of the inserted variables with an "outside" variable or not, if it is possible, the "inside" variable is replaced by the "outside" variable; among all of the possible swaps, the swap that result in the largest increase in $R^{2}$ is done. After that, if it is possible to increase $R^{2}$ by inserting a third variable, the variable that leads to the largest increase in $R^{2}$ will be inserted into the model, and so on. This process continues until either it is not possible to increase $R^{2}$ more or there would not be any variable left to be inserted into the model, in addition it is necessary to mention that we decided to insert only the regressors which are all statistically significant at the $10 \%$ level.

2) After finding the forecasting model in the first step, one-step-ahead is forecasted by the model.

3) The next observation is added to the data set, and again steps 1 and 2 are repeated.

It is obvious that this method requires so many estimations, and we cannot supply the reader the results of the estimations; however, some of the main results are displayed graphically. The results are as follows:

- The recursively computed values of the correlation between the actual returns and the forecasted returns.

- The recursively computed values of the root mean square prediction error (RMSPE). 
- The directional accuracy of the forecasts (we made a series that takes the value of unity if the direction of change in the log price is forecasted correctly, and zero otherwise.

- The importance of each regressor, which is identified by the number of times that the lags of the regressor are inserted in the selected model. The more the regressor is inserted, the more important it is in forecasting.

\section{STATISTICAL TESTS}

\section{1. Non-parametric test of predictive performance}

In this subsection and the next one, we explain two statistical tests which are used for assessing predictability. Pesaran and Timmermann (1992) proposed a test statistic whose focus is on the correct forecast of the direction of change in the variable under consideration.

This test is based on the portion of times that the direction of change in the variable is correctly forecasted. Let $\hat{y}$ be the predictor of $y, p_{y}=\operatorname{Pr}\left(y_{t}>0\right), p_{\hat{y}}=\operatorname{Pr}\left(\hat{y}_{t}>0\right)$, and $\hat{p}$ the portion of times that the sign of $y_{t}$ is correctly forecasted. The test statistic is:

$$
P T=\frac{\hat{p}-\hat{p}_{*}}{\left(\hat{v}(\hat{p})-\hat{v}\left(\hat{p}_{*}\right)\right)^{\frac{1}{2}}} \sim N(0,1)
$$

where:

$$
\begin{aligned}
& \hat{p}=\frac{1}{n} \sum_{t=1}^{n} \operatorname{Sign}\left(\hat{y}_{t} y_{t}\right), \hat{p}_{*}=\hat{p}_{y} \hat{p}_{\hat{y}}+\left(1-\hat{p}_{y}\right)\left(1-\hat{p}_{\hat{y}}\right) \\
& \hat{v}(\hat{p})=\frac{1}{n} \hat{p}_{*}\left(1-\hat{p}_{*}\right), \hat{v}\left(\hat{p}_{*}\right)=\frac{1}{n}\left(2 \hat{p}_{y}-1\right)^{2} \hat{p}_{\hat{y}}\left(1-\hat{p}_{\hat{y}}\right)+\frac{1}{n}\left(2 \hat{p}_{\hat{y}}-1\right)^{2} \hat{p}_{y}(1- \\
& \left.\hat{p}_{y}\right)+4 \frac{1}{n^{2}} \hat{p}_{y} \hat{p}_{\hat{y}}\left(1-\hat{p}_{\hat{y}}\right)\left(1-\hat{p}_{y}\right)
\end{aligned}
$$

The null hypothesis of the test is that $y_{t}$ and $\hat{y}_{t}$ are distributed independently, in other words, $\hat{y}_{t}$ has no power in forecasting $y_{t}$.the $95 \%$ and $99 \%$ critical values are 1.64 and 2.33 respectively.

\section{2. Testing for zero correlation between the forecasted values and the actual values}

In fact, correlation coefficient between the actual returns $r$ and the forecasted returns $\hat{r}$ shows the fit of the forecasting model. To test whether the correlation coefficient is statistically zero or not, the following statistics is used:

$$
t=\frac{\hat{\rho}}{\sqrt{\frac{1-r^{2}}{n-2}}}
$$

where $\hat{\rho}$ is the correlation coefficient between $r$ and $\hat{r}$. Under the null hypothesis of $\rho=0, t$ has a student's distribution with $n$ - 2 degrees of freedom (see Chiang, 2003, p. 291-292). 


\section{EMPIRICAL RESULTS}

To see whether the stocks returns are predictable using publicly available information or not, we used monthly observations on Tehran Exchange Price Index (TEPIX) and some relevant economic variables from 2000:1 to 2011:12. The first forecast of each return was computed in 2008:1 and the observations before this date were used as a preliminary "training" period for estimation.

The economic variables which were used for computing multiple-step-ahead forecasts of the stock returns, consistent with the approach of many other studies, include money supply, gold price in domestic currency, exchange rate (Iranian Rial to US Dollor Rate, IRR/USD), Iran oil revenues and non-oil trade balance obtained from various issues of the bulletins published by the Central Bank of Iran. All variables except trade balance are transformed as growth rate or $\log$ differenced. Trade balanced is defined as $\log$ (Import/non oil export). Lag length is specified by Schwarz Bayesian criterion (SBC)

As it can be seen in Table 1, all Pesaran-Timmermann (PT) test statistics are bellow 2.33, the $99 \%$ critical value for a one sided test. In other words, the returns are not predictable at conventional levels. In addition, all sample correlation coefficients between $r$ and $\hat{r}$ are statistically insignificant at conventional levels. The last column shows the proportion of times the sign of the returns is not correctly predicted.

Table1. Non-parametric Statistic of Pessaran-Timmermann (PT).

\begin{tabular}{|c|c|c|c|c|c|}
\hline Exchange rate & PT & $\begin{array}{c}\text { p-value of the } \\
\text { PT test statistic }\end{array}$ & $\begin{array}{c}\text { Correlation } \\
\text { coefficient }\end{array}$ & $\begin{array}{c}\text { p-value for the } \\
\text { null of zero } \\
\text { correlation }\end{array}$ & $\begin{array}{c}\text { proportion of } \\
\text { correct signs \% }\end{array}$ \\
\hline One-step ahead & 1.29 & 0.21 & 0.12 & 0.38 & $51.5 \%$ \\
\hline two-step ahead & 1.10 & 0.34 & 0.11 & 0.42 & $42.2 \%$ \\
\hline three-step ahead & 0.98 & 0.44 & 0.10 & 0.63 & $41.1 \%$ \\
\hline four-step ahead & 0.91 & 0.50 & 0.08 & 0.66 & $40.4 \%$ \\
\hline five-step ahead & 0.94 & 0.48 & 0.09 & 0.59 & $43.4 \%$ \\
\hline
\end{tabular}

\section{CONCLUSION}

In this article, we examined predictability of monthly stock return of Tehran Exchange Price Index (TEPIX) based on monthly data from 2000:1 to 2011:12 using publicly available information on some relevant economic variables including money supply, gold price, exchange rate (IRR/USD), oil revenues and non-oil trade balance. The multi-step-ahead forecasts of the returns of the exchange rates were computed using publicly available information by a recursive estimation method in which the parameter estimates were updated recursively in light of new monthly observations, and also its regressors were changed recursively according to the $\mathrm{SBC}$ criterion. Then predictability was tested using a nonparametric test of predictive performance which has been proposed by Pesaran and Timmermann in 1992. The results showed that the returns are not predictable. 


\section{References}

[1] Amemiya, T. (1980). Selection of regressors. International Economic Review, 21, 331-345.

[2] Bossaerts, P., Hillion, P. (1999). Implementing statistical criteria to select return forecasting models, Review of Financial Studies, 12(2), 405-428.

[3] Chen, S. S., Chen, H. C. (2007). Oil prices and real exchange rates. Energy Economics, 29(3), 390-404.

[4] Chiang, C. L. (2003). Statistical methods of Analysis. World Scientific Publishing: Singapore.

[5] Chortareas, G., Jiang Y.' Nankervis, J. C. (2010). The random-walk behavior of the EURO exchange rate. Finance Research Letters, 8(3), 158-162.

[6] Derksen, S., H. J. Keselman (1992). Backward, Forward and Stepwise Automated Subset Selection Algorithms: Frequency of Obtaining Authentic and Noise Variables. British Journal of Mathematical and Statistical Psychology, 45, 265-282.

[7] Ehrmann, M., Fratzscher, M. (2005). Exchange rates and fundamentals: new evidence from real-time data. Journal of International Money and Finance, 24(2), 317-341.

[8] Fama, E. F. (1970). Efficient capital markets: a review of theory and empirical work. Journal of Finance, 25, 83-417.

[9] Fama, E. F. (1991). Efficient capital markets II. Journal of Finance, 46, 1575-1617.

[10] Lien, K. (2009). Day Trading \& Swing Trading the Currency Market. $2^{\text {nd }}$ ed. New Jersey: John Wiley \& Sons.

[11] Malkiel, B. (1992). Efficient market hypothesis. New Palgrave Dictionary of Money and Finance. London: Macmillan.

[12] Pesaran, M. H., Timmermann, A. (1992). A simple nonparametric test of predictive performance. Journal of Business and Economic Statistics, 10(4), 461-465.

[13] Pesaran, M. H., Timmermann, A. (1995). Predictability of Stock Returns: robustness and economic significance. Journal of Finance, 50(4), 1201-1228.

[14] Pesaran, M. H., Timmermann, A. (2000). A Recursive Modeling Approach to Predicting UK stock Returns. The Economic Journal, 110(460), 159-191.

[15] Pesaran, M. H., Timmermann, A. (1994). Forecasting stock returns An examination of stock market trading in the presence of transaction costs. Journal of Forecasting, 13, 330-365.

[16] Roberts, H. (1967). Statistical versus clinical prediction of the stock market. Unpublished manuscript. Center for Research in Security Prices, University of Chicago.

[17] Samuelson, P. (1965). Proof that Properly Anticipated Prices Fluctuate Randomly. Industrial Management Review, 6, 41-49. 
[18] Mohsen Mehrara, Maysam Musai (2013). Ranking of developing countries Based on the Economic Freedom Index. International Letters of Social and Humanistic Sciences, $2,32-38$.

[19] Mohsen Mehrara, Maysam Musai (2013). The relationship between Economic Growth and Human Capital in Developing Countries. International Letters of Social and Humanistic Sciences 5, 55-62.

[20] Mohsen Mehrara, Maysam Musai (2013). The Causality between Capital Formation and Economic Growth in MENA Region. International Letters of Social and Humanistic Sciences, 8, 1-7. 